\title{
Un análisis de columnas de opinión desde la metáfora conceptual
}

\author{
An Analysis of Opinion Pieces according to the Conceptual Metaphor \\ Uma análise de colunas de opinião desde a metáfora conceitual
}

Paola Alarcón Hernández ${ }^{\text {a }}$

Universidad de Concepción, Chile

palarco@udec.cl

ORCID: http://orcid.org/0000-0001-7217-5668

Claudio Diaz Larenas

Universidad de Concepción, Chile

ORCID: http://orcid.org/0000-0002-9024-2497

Victor Vásquez Bustos

Universidad de Concepción, Chile

Redalyc: http://www.redalyc.org/autor.oa?

$\mathrm{id}=0000-0003-1334-9896$
DOI: https://doi.org/10.11144/Javeriana.syp37-73.acom Redalyc: http://www.redalyc.org/articulo.oa?id=86058735007

Fecha de recepción: 15 Enero 2018

Fecha de aprobación: 31 Agosto 2018

Fecha de publicación: 30 Diciembre 2018

\section{Resumen:}

Se presenta una aproximación desde la Lingüística Cognitiva al análisis del discurso en los medios de comunicación. El objetivo de esta investigación de tipo cualitativa es analizar las metáforas conceptuales referentes a la educación pública en columnas de opinión. Se aplicó un análisis de contenido para la metáfora a dos columnas de opinión de 2017 de dos cibermedios chilenos. Los resultados muestran que las metáforas permiten conceptualizar y caracterizar de forma precisa los puntos de vista expuestos en las columnas. En particular, las metáforas conceptuales analizadas evidencian el carácter complejo del concepto de educación pública mediante su asociación principalmente con dos dominios fuente: botín y edificio, con lo cual se destacan determinadas características y valoraciones. Asimismo, ambas columnas coinciden en que la situación actual se debe a las políticas adoptadas por el estado chileno, caracterizado de manera negativa a través de la atribución metafórica de rasgos humanos como la cobardía.

Palabras clave: metáfora conceptual, Lingüística Cognitiva, columna de opinión, educación pública, cibermedios.

\section{Abstract:}

This paper provides an approach to the discourse analysis applied to the media under the Cognitive Linguistics. This qualitative research aims to analyze the conceptual metaphors related to the public education found in the opinion pieces. A content analysis for conceptual metaphors was carried out in two opinion pieces posted in 2017 in two Chilean cyber-media. The results show that the metaphors allow to conceptualize and characterize accurately the viewpoints communicated in the opinion pieces. In particular, the conceptual metaphors analyzed show the complex nature of the concept Public Education by associating it mostly with two source domains, loot and building, which emphasize some characteristics and valuation. Likewise, both opinion pieces coincide that the current situation is due to the policies adopted by the Chilean State, which is characterized negatively in those pieces by using the metaphor to attribute it some human traits like the cowardice.

Keywords: conceptual metaphor, Cognitive Linguistics, opinion piece, public education, cyber-media.

\section{Resumo:}

Apresenta-se uma aproximação desde a Linguística Cognitiva à análise de discurso na mídia. O objetivo desta pesquisa de tipo qualitativa é analisar as metáforas conceituais referentes ao ensino público em colunas de opinião. Uma análise de conteúdo para a metáfora a duas colunas de opinião de 2017 foi aplicado a dois cibermeios chilenos. Os resultados demostram que as metáforas permitem conceituar e caracterizar de forma precisa os pontos de vista expostos nas colunas. Em particular, as metáforas conceituais analisadas evidenciam o carácter complexo do concepto de educação pública mediante sua associação principalmente com dois domínios fonte: espólio e construção, com o qual destacam-se determinadas características e valorações. Além disso, ambas as

Notas de autor: 
colunas concordam em que a situação atual é devido às políticas adotadas pelo estado chileno, caracterizado de maneira negativa pela atribuição metafórica de traços humanos como a covardia.

Palavras-chave: metáfora conceitual, Linguística Cognitiva, coluna de opinião, ensino público, cibermídia.

\section{Introducción}

En la actualidad se observa un creciente uso de los medios de comunicación electrónicos. En Chile, casi todos los periódicos tradicionales en papel tienen una versión en línea, y hay otros medios que funcionan exclusivamente por esta vía. Asimismo, los medios consideran índices de lectura y promueven la interacción con sus lectores, por lo que muchos de ellos publican noticias en redes sociales como Facebook. En este contexto, el presente estudio muestra una aproximación desde un enfoque lingüístico más bien reciente, como es la Lingüística Cognitiva, al análisis del discurso en los medios de comunicación.

Tradicionalmente cada medio tenía columnistas estables, con cierto prestigio o conocimiento nacional. Hoy se observa que este espacio de opinión se abre a más ciudadanos. Junto con ello, cualquier persona u organización social que cuente con los recursos para hacerlo, puede implementar un sitio web desde el cual presentar sus opiniones. Así, hoy en día hay mayor variedad de columnistas quienes pueden exponer sus puntos de vista y generar debate en torno a temas contingentes para el país en su conjunto o para determinados grupos de interés.

En Chile, la educación es una de las áreas de la sociedad que suscita mayor debate público, ya sea por las transformaciones que se proponen a partir de proyectos de ley o por las demandas y movimientos sociales que se generan por parte de los actores involucrados. En 2017, el gobierno de la coalición de izquierda, La Nueva Mayoría, encabezado por la presidenta del país, Michelle Bachelet, propuso el proyecto de ley Nueva Educación Pública, que pretende abordar algunas de las falencias del actual sistema educacional chileno. No obstante, desde el profesorado y otros actores surgió una serie de críticas a este proyecto, que se expresaron tanto en las calles como en los medios de comunicación; particularmente, en columnas de opinión, como se mostrará en este artículo. Esta visión crítica se comprende en el contexto de las transformaciones que ha experimentado la educación pública en Chile.

Un hito fundamental en la historia reciente de la educación chilena es que durante el gobierno de la dictadura cívico-militar en el año 1980 "se transfirió la administración de los establecimientos educacionales públicos a los municipios y se incentivó la provisión de servicios educacionales por parte del sector privado" (Mizala y Romaguera, 1998, pp. 4-5). Como resultado, se establecieron tres tipos de colegios: municipalizados, particulares subvencionados por el estado y particulares pagados. De acuerdo con Mizala y Romaguera (1998):

El proceso de descentralización que se inicia a comienzos de los 80 implicó que la administración de los establecimientos escolares del sector público fuera transferida a las municipalidades. La reforma también permitió la incorporación del sector privado como oferente de servicios educacionales financiados con recursos públicos, al establecer un sistema de subvención por alumno, en un esquema de voucher. En un sistema clásico de subvención (voucher) el gobierno realiza un pago a las familias de forma que ellas puedan matricular a sus hijos en el colegio de su elección (público o privado). (pp. 4-5)

Otro cambio importante en la década de los ochenta es que "los docentes de los establecimientos fiscales pasaron a regirse por la legislación laboral del sector privado, perdiendo su calidad de funcionarios públicos, norma que posteriormente se modificaría en el año 1991" (Mizala y Romaguera, 1998, pp. 4-5). De allí que una de las demandas más sostenidas por los docentes sea el pago de lo que se conoce como la Deuda Histórica de los profesores, la cual:

se originó por el incumplimiento de la Ley No 3.551 de 1981, que dispuso un reajuste del sueldo base al sector público, estableciendo en su artículo 40 una 'asignación especial' no imponible para el personal docente dependiente del Ministerio de Educación. Como resultado de la municipalización impuesta a partir del año 1981, la mayoría de los profesores no alcanzaron 
a recibir el 100\% de la asignación, pues al ser traspasados al sector municipal, los nuevos empleadores desconocieron los derechos adquiridos por los profesores. (Colegio de Profesores de Chile, s. f.)

El proyecto de Nueva Educación Pública fue observado atentamente por el profesorado, dado que las expectativas eran altas. Surgió, entonces, un movimiento desde un sector de los docentes que se opone a dicho proyecto, lo cual fue recogido por los medios de comunicación como noticias y también otorgó espacio a los profesores para que expusieran su opinión.

Dado este contexto, en este estudio se presenta un análisis de dos columnas de opinión recogidas de dos cibermedios: La Tercera y el sitio web del Colegio de Profesores de Chile. Se pretende abordar el discurso de los columnistas desde la perspectiva de la metáfora conceptual, que se enmarca en la Lingüística Cognitiva (sección 2). De acuerdo con este enfoque, lo que tradicionalmente se consideraba una figura literaria se entiende más bien como una forma de conceptualizar la realidad. En consecuencia, el objetivo de esta investigación de tipo cualitativa (sección 3) es analizar las metáforas conceptuales con las cuales los columnistas configuran la educación pública. Como se desarrollará en el análisis (sección 4), ambas columnas utilizan la metáfora conceptual para expresar una visión crítica sobre la educación pública y el estado de Chile.

\section{Marco teórico}

\section{Lingüística Cognitiva}

Se reconoce en Chomsky el inicio del giro cognitivo en la lingüística contemporánea (Taylor, 2002), en lo que algunos llaman la revolución chomskiana, al definir al lenguaje como un fenómeno mental; con ello, confrontó los principios del conductismo y su incidencia sobre la lingüística. No obstante, un grupo de investigadores en semántica generativa como Lakoff, Postal, Ross y McCawley, manifestaron que el Generativismo carecía de una aproximación al lenguaje que incorporara aspectos semánticos, que tomara en consideración habilidades cognitivas generales y que atendiera al uso del lenguaje en contextos determinados (Dąbrowska y Divjak, 2015; Taylor, 2002). Esta disidencia permite explicar el inicio de la Lingüistica Cognitiva (LC) a finales de los años setenta.

En esta corriente se concibe el lenguaje como un instrumento para organizar, procesar y portar conocimiento (Cuenca y Hilferty, 1999; Taylor, 2002; Evans y Green, 2006; Geeraerts y Cuyckens, 2007; Ibarretxe-Antuñano y Valenzuela, 2012). Esta concepción del lenguaje se sustenta en principios que dan unidad a los distintos enfoques dentro de la LC y que constituyen la base de este estudio.

Un principio fundamental de la LC es la centralidad del significado para el análisis lingüístico. La gramática se entiende como la estructuración y simbolización de contenido semántico (Geeraerts y Cuyckens, 2007; Hart, 2014; Langacker, 1987, 2008). En consecuencia, el significado es un concepto fundamental y no derivado en el análisis gramatical, a diferencia de las teorías formalistas. Otro principio es que el lenguaje es un sistema para la conceptualización del mundo; por lo tanto, no se requiere postular un nivel estructural de significado lingüístico diferente del nivel en que el conocimiento de mundo se asocia con las formas lingüísticas, en lo que algunos autores llaman el carácter enciclopédico del significado lingüístico (Geeraerts y Cuyckens, 2007, p. 5). Un principio central en LC es que el lenguaje es corporeizado, es decir, el lenguaje surge de la clase de experiencias que tenemos con nuestros cuerpos y el entorno físico en el que vivimos (Casasanto, 2014; Lakoff y Johnson, 1999).

Un principio relevante para el presente estudio es que el conocimiento del lenguaje surge del uso (Croft y Cruse, 2004/2008), según el cual se deben desarrollar los llamados modelos basados en el uso (Barlow y Kemmer, 2000). Al hacerlo, la LC debe basarse en corpora de origen natural que hagan posible proveer teorías cognitivamente plausibles a pruebas empíricas. Por tanto, la LC se inscribe dentro de las corrientes 
funcionalistas, dado que la conceptualización no es simplemente un proceso cognitivo, pues se orienta a un propósito en un acto comunicativo.

Junto con la dimensión cognitiva, el lenguaje también puede ser explicado apelando a sus principales funciones, esto es, la comunicación y la mantención de la cohesión social (Dąbrowska y Divjak, 2015). Ambas perspectivas no son excluyentes, sino complementarias, dado que la cognición humana es inherentemente social (Tomasello, 1999). Aunque en LC se reconoce esto, solo recientemente los investigadores han comenzado a integrar las perspectivas cognitiva y social, en lo que se conoce como el giro social de la LC (Croft, 2009; Dąbrowska y Divjak, 2015; Romano y Porto, 2016). Morales-López propone incluso una visión más constructivista del conocimiento, en la cual se concibe al sujeto como un constructor activo de sus estructuras cognitivas, principalmente por medio del lenguaje/discurso. Coincidentemente, Koller (2012) señala que la cognición crea una instancia del discurso, a la vez que es moldeada por él; esto implica que las representaciones están culturalmente ligadas y que ocurren en determinados momentos históricos.

En consecuencia, este estudio atiende a la dimensión socio-cognitiva del discurso (Chilton, 2004; Landau, Robinson y Meier, 2014; Romano y Porto, 2016; Van Dijk, 2003, 2009), la cual “implica abordar con mayor profundidad la noción de discurso al aunar conjuntamente estas dos realidades (la social y la cognitiva), que son inseparables del lenguaje" (Morales-López, 2011, p. 9).

Un concepto fundamental para el análisis del discurso en LC es la conceptualización, esto es, la habilidad de construir la misma situación de maneras alternativas (Langacker, 2015, p. 119). El lenguaje nos puede llevar a ver la situación o evento descrito de diferentes maneras. Estas conceptualizaciones alternativas o "formas de ver" dependen de los parámetros de conceptualización, e incluyen lo que elegimos mirar, a qué elementos prestamos más atención, etc. (Langacker, 2008, p. 55). Entre las operaciones de conceptualización se encuentran: la metáfora conceptual, la metonimia, el perfilamiento y la categorización. En consecuencia, el análisis del discurso en LC se centra en el valor cognitivo de las construcciones lingüísticas, en el cual el lenguaje sirve como un indicador de una serie de operaciones de conceptualización, las cuales producen una representación particular de la realidad.

\section{Metáfora conceptual}

Uno de los enfoques con mayor desarrollo en LC es la metáfora conceptual, la cual se produce por la proyección de elementos, propiedades y principios inferenciales de un dominio más concreto (dominio fuente) a otro dominio más abstracto (dominio meta) (Ibarretxe-Antuñano, 2013; Kövecses, 2002/2010; Soriano, 2012). Este conjunto de correspondencias entre ambos dominios define el carácter conceptual de la metáfora, tal como lo establecieron Lakoff y Johnson (1980/2012) en Metáforas de la vida cotidiana. Estos autores pusieron de relieve que la metáfora no es solo asunto de palabras, sino que se manifiesta en nuestra forma de razonar y de concebir nuestra experiencia. En este marco, se sostiene que la metáfora impregna el discurso cotidiano y se usa de manera inconsciente y automática. Kövecses (2015) señala que esta definición debe incorporar el contexto para dar cuenta acabada de la producción de las metáforas y del significado de las construcciones metafóricas, como muestran los estudios sobre el discurso metafórico (Musolff y Zinken, 2009; Semino, 2008).

Desde la perspectiva socio-cognitiva, Gibbs (2014, p. 30) plantea que aunque los conceptos metafóricos sean esenciales para ciertos aspectos del pensamiento abstracto, típicamente emergen en contextos específicos en los cuales las personas pretenden coordinar mejor sus propias acciones y sus interacciones con otras. De esta forma, las metáforas conceptuales son cognitivas, en el sentido de modelar el pensamiento; y sociales, en el sentido de facilitar las conductas sociales de las personas. En el ámbito del discurso sobre la economía, por ejemplo, Soares da Silva (2016) afirma que la metáfora, en cuanto estrategia discursiva de persuasión, es un tópico relevante, desde la concepción del lenguaje como producto de la cognición socioculturalmente situada. En educación, se ha usado como una herramienta de obtención y análisis de las representaciones sobre el 
profesorado, atendiendo también a factores contextuales (Saban, 2006; Thomas y Beauchamp, 2011; Moser, 2000; Saban, Kocbeker y Saban, 2007; Saban, 2010; Alarcón-Hernández, Vergara-Morales, Concha-Moreno y Díaz-Larenas, 2014; Alarcón-Hernández, Díaz-Larenas y Vergara-Morales, 2015; Alarcón-Hernández, Díaz-Larenas, Venegas-Carrasco y Vásquez-Bustos, 2018).

Muchas metáforas tienen como dominio fuente un esquema de imagen, esto es, "un patrón recurrente, una forma y una regularidad en o de esas actividades de ordenamiento en curso" (Johnson 1987/1991, p. 85), que le aporta sus elementos estructurantes y principios inferenciales a los dominios meta a los que se proyecta. Así, cuando se selecciona esquema del contenedor para hablar de agrupaciones sociales (por ejemplo, un sindicato o colegio profesional), su lógica interna configura el evento en términos de inclusión-exclusión: se está dentro o fuera de la agrupación, se puede ser expulsado de esta, etc.

De acuerdo con Lakoff y Johnson (1980/2012) existe un tipo de metáfora, la llamada metáfora ontológica, que corresponde a "nuestras formas de considerar acontecimientos, actividades, emociones, ideas, etc., como entidades o sustancias" (p. 64). Al comprender las experiencias como objetos y sustancias se puede tratar partes de la experiencia como entidades discretas. Según los autores, "una vez que hemos identificado nuestras experiencias como objetos o sustancias podemos referirnos a ellas, categorizarlas, agruparlas y cuantificarlas "y, de esta manera, razonar sobre ellas" (Lakoff y Johnson, 1980/2012, p. 63). La personificación, que tradicionalmente se ha considerado una figura retórica distinta de la metáfora, es desde la perspectiva conceptual un tipo de metáfora ontológica. Como se mostrará en el análisis, mediante la personificación, un "objeto físico se especifica como persona. Esto nos permite comprender una amplia diversidad de experiencias con entidades no humanas en términos de motivaciones, características y actividades humanas" (Lakoff y Johnson, 1980/2012, p. 71).

Finalmente, otro tipo de metáfora que es abordada en este estudio es la metáfora orientacional, la cual “organiza un sistema global de conceptos con relación a otro" (Lakoff y Johnson, 1980/2012, p. 50). Muchas veces, el dominio fuente es un dominio espacial completo, por ejemplo, arriba-abajo, que configura otros dominios, lo cual da lugar a metáforas orientacionales como feliz es arriba-triste es abajo. En otras palabras, la orientación espacial arriba-abajo, en su totalidad, se corresponde con un dominio que cubre el campo emotivo de la felicidad y la tristeza. De acuerdo con Lakoff y Johnson, las orientaciones espaciales surgen de la experiencia física y cultural.

\section{Columnas de opinión en cibermedios}

Las columnas de opinión "tienen como finalidad definir la postura del autor respecto a la situación a la que hace referencia en su escrito. De este modo, los comentarios presentan evidencias del evento al que se refiere en el desarrollo de la columna" (Arancibia y Montecino, 2013, p. 139). Sin embargo, dada la irrupción de los medios digitales, observamos hoy en día una transformación de los tradicionales medios escritos en ciberperiódicos, esto es, medios con versión en papel y electrónica, o medios exclusivamente electrónicos.

Así también han evolucionado las formas de interacción entre productores de texto y receptores, y entre estos mismos, lo cual se manifiesta en los comentarios a las columnas. Tradicionalmente, la columna de opinión de los medios escritos recibía reacciones mediante otra columna o bien de 'cartas al director'. Hoy, cualquier columna que esté en formato electrónico está disponible para que todos ciberciudadanos puedan opinar, "estableciendo una especie de igualdad entre su comentario y la opinión vertida por el político (Fairclough y Fairclough, 2012; Montecino y Arancibia, 2013)" (Montecino y Arancibia, 2015, p. 162). Muchos de estos medios replican las columnas en Facebook, con lo cual aumentan la lectura y participación de los lectores.

Se observa entonces "el surgimiento, de manera relativamente estable, de una esfera pública digital -lugar virtual y discursivo - que abre un espacio al debate ciudadano sobre asuntos que afectan a las organizaciones políticas y al funcionamiento de instituciones" (Montecino y Arancibia, 2015, p. 160). 
En el ámbito de la educación, en las diversas opiniones manifestadas en columnas de opinión de ciberperiódicos, los columnistas expresaron sus posiciones con respecto al movimiento del profesorado lo que es sustancial para este estudio- sus visiones sobre este, lo que constituye diferentes representaciones sociales, en las cuales se distingue un conjunto de atributos y evaluaciones.

\section{Metodología}

La presente investigación se enmarca dentro del paradigma interpretativo de investigación. Hernández, Fernández y Baptista (2010) afirman que el paradigma interpretativo, también llamado paradigma cualitativo, se centra en el estudio de los significados de las acciones humanas y de la vida social. Según lo anterior, se implementó una metodología de tipo cualitativo cuyo alcance es descriptivo exploratorio, dado que, si bien pretende describir un fenómeno, como es requisito para los estudios de tipo descriptivo (Hernández et al., 2010), no existen referencias contundentes sobre trabajos que utilicen los mismos conceptos teóricos que la investigación, por tanto, tiene un carácter exploratorio.

\section{Corpus}

La unidad de análisis son las columnas de opinión disponibles en ciberperiódicos a la fecha de realizar la investigación. El corpus seleccionado se basó en un muestreo por criterio, el que según (Mejía, 2000) consiste en seleccionar aquellas unidades que cumplen con criterios predefinidos por el equipo de investigación. Como criterios se establecieron: el tema (educación pública y Nueva Ley de Educación Pública) y el lapso temporal (año 2017), los cuales se justifican porque en ese año se generó debate en torno a la educación pública en los medios de comunicación a partir de la discusión sobre dicho proyecto de ley. Se seleccionaron las siguientes columnas:

TABLA 1

Corpus

\begin{tabular}{llll}
\hline Título & Autor & Medio & Fecha \\
\hline $\begin{array}{llll}\text { 1. NEP: ¿Nueva educación pública } \\
\text { o... neoestado privatizador? }\end{array}$ & $\begin{array}{l}\text { Marcelo Castillo, } \\
\text { Profesor de } \\
\text { Educación General } \\
\end{array}$ & $\begin{array}{l}\text { Sitio web del } \\
\text { Colegio de } \\
\text { profesores }\end{array}$ & $\begin{array}{l}\text { 12 Junio, } \\
2017\end{array}$ \\
\hline $\begin{array}{l}\text { Nueva Educación Pública: } \\
\text { ¿Dónde están los profesores de } \\
\text { Chile? }\end{array}$ & $\begin{array}{l}\text { César Solís, Profesor } \\
\text { de Historia }\end{array}$ & La Tercera & 17 agosto, \\
& & & 2017 \\
\hline
\end{tabular}

Fuente: elaboración propia

\section{Procedimiento de análisis}

Como técnica de análisis de datos se utilizó el análisis de contenido inductivo. Según Ruiz (2009), esto significa que una vez seleccionado el corpus se identifican aquellos fragmentos de discurso relevantes para la investigación y se les asigna un código que emerge desde el texto. Las ilustraciones de las redes conceptuales asociadas al sistema de categorías de análisis son elaboradas con el software Atlas.Ti. 
El análisis de la metáfora conceptual se basó en las propuestas de análisis de contenido para la metáfora (Moser, 2000; Saban et al., 2007; Saban, 2010; Alarcón-Hernández et al., 2014, 2015, 2018). En consecuencia, se siguieron las siguientes etapas para la investigación: (1) preanálisis, (2) etiquetado, (3) clasificación (clarificación y eliminación), y (4) juicio de pares.

En la etapa de preanálisis, "se diseñan y definen las etapas específicas por medio de las cuales se examinarán los datos y se organizará el material a analizar" (Alarcón-Hernández et al., 2018, p. 72). Luego, en el etiquetado, se elabora una lista de las metáforas identificadas. Se codifica el nombre del dominio fuente (por ejemplo: botín, edificio).

En la etapa de clarificación de las metáforas se identifican sus componentes en las expresiones metafóricas: dominio meta, dominio fuente y correspondencias. El dominio meta es el concepto a ser metaforizado (en esta investigación, profesorado, educación, etc.). El dominio fuente es el concepto con el que se configura el dominio meta. Las correspondencias son las relaciones que se establecen entre ambos dominios. En esta etapa se considera el contraste entre el significado básico (concreto) del concepto de dominio fuente y el significado contextual, esto es, aquel que tiene en el dominio de la educación (dominio meta), de acuerdo con un procedimiento propuesto por Pragglejaz Group (2007). Por ejemplo, en este extracto: "la implementación en los colegios de programas recetarios que tienen como único objetivo mejorar los resultados en las pruebas estandarizadas, transformando al profesor en un mero ejecutor de dichas recetas /.../" (Boric y López, 2015), el significado concreto de receta contrasta con el significado contextual, que está en el dominio del sistema educativo, en el cual se configura el desempeño docente en términos de ceñirse a las instrucciones del Ministerio de Educación. Luego de esta parte, se eliminan las respuestas que no son metafóricas, es decir, son descripciones literales. Por ejemplo, "el profesor es como un educador de los jóvenes", donde no hay un dominio fuente involucrado.

Cada investigador realizó el análisis individualmente; luego, en la etapa de juicio de pares, por separado. Posteriormente, los resultados se sometieron a discusión grupal, a fin de lograr consenso y asegurar la fiabilidad de los datos.

\section{Resultados}

Mediante el análisis de contenido se identificaron dos dominios metapredominantes en el corpus: el estado chileno y la educación pública. En la figura 1 se exponen los dominios meta y sus respectivos dominios fuente. 


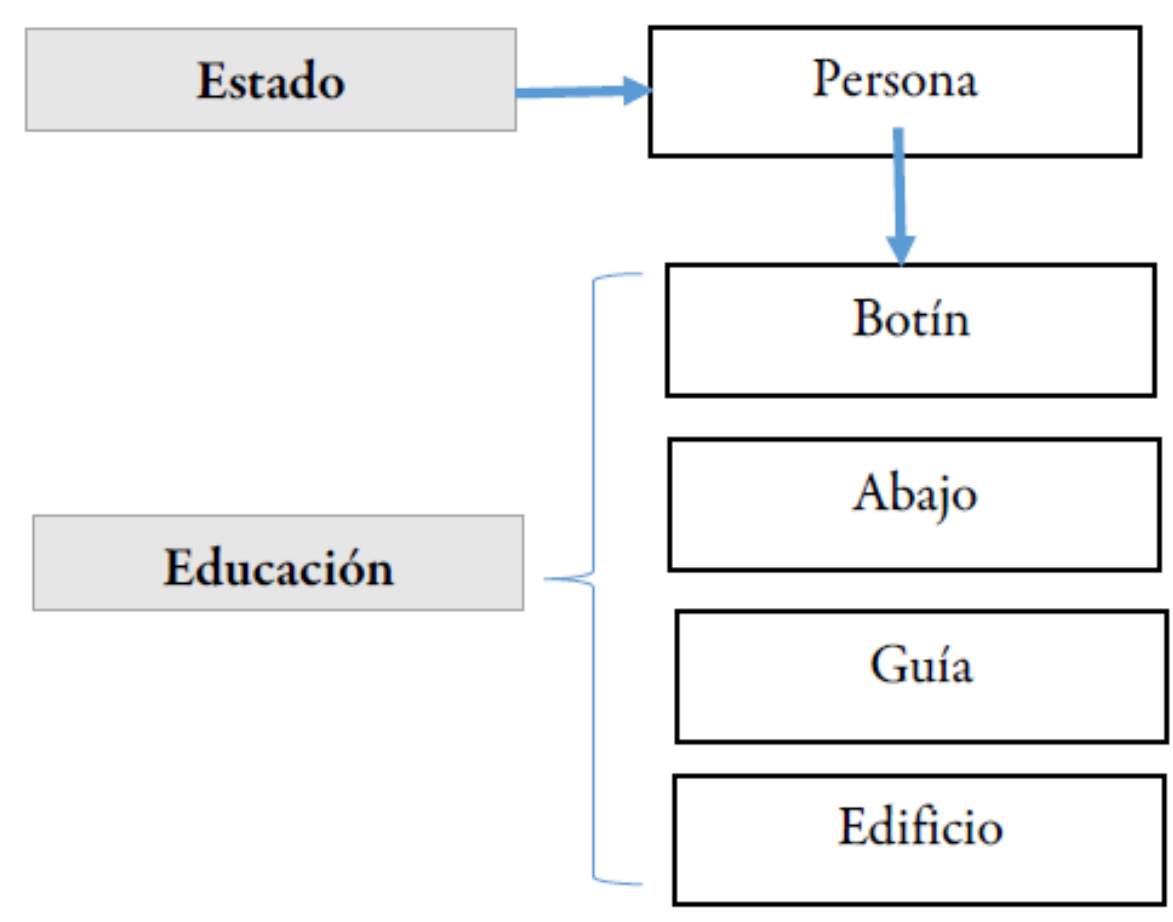

FIGURA 1.

Dominios meta y dominios fuente

Fuente: elaboración propia

Ambas columnas abordan críticamente el proyecto de ley Nueva Educación Pública (NEP) impulsado por el gobierno de Michelle Bachelet, y coinciden en que la situación actual se debe a que el estado chileno durante el gobierno cívico-militar de Pinochet incentivó la privatización de la educación y dejó en la administración de los municipios los establecimientos que antes dependían directamente del estado. Para los autores, esa reforma ha impactado negativamente en la calidad de la enseñanza y en las condiciones laborales de los docentes. Los autores asumen que dicho proyecto no producirá modificaciones sustanciales al modelo educacional impuesto por el gobierno dictatorial.

\section{“NEP: ¿nueva educación pública o... neo estado privatizador?”}

En esta columna, el autor, Marcelo Castillo, profesor de educación general básica, aboga por una refundación de la educación pública y critica que una parte de los establecimientos educacionales sea administrada por particulares. En sus palabras, "el sentido común dice que es imposible que una educación atomizada y sistemáticamente entregada a intereses privados, pueda definir una identidad y un modelo de desarrollo país, porque ello es misión inherente e irrenunciable de una Educación Pública de Estado”. Aludiendo, entonces, al rol del Estado, Castillo recurre a la personificación el estado es una persona:

1. [la educación pública] es la encargada de educar en valores ciudadanos comunes, encaminar hacia un proyecto común de futuro. Reitero, una Educación Pública de Estado, pero no hablo de este Estado cobarde, subsidiario, que desde la dictadura hasta la actual "democracia" chilensis, ha vendido su alma a los grupos económicos.

Castillo usa la personificación para asignar a los sucesivos gobiernos desde la dictadura la responsabilidad de haber entregado la educación pública al sector privado y de haber cedido ante la influencia de los sectores económicos. Esta afirmación se comprende en la crítica de Castillo a la ley NEP que formula el gobierno de Bachelet. Según el autor, esta ley tiene rasgos de gatorpardismo, pues propone la desmunicipalización, 
pero sin implementar cambios fundamentales al actual sistema, con lo cual se entiende parte del título de la columna: "neoestado privatizador". De acuerdo con él, esta ley no revertirá "el enorme daño causado desde la municipalización iniciada desde 1981 en adelante”. El autor afirma que se propone una ley que "mantiene el nocivo sistema de financiamiento, la lógica gerencial de sostenedores".

Al mismo tiempo, Castillo usa la metáfora conceptual las actividades con propósito son viajes para destacar la importancia que tiene la educación pública en la formación de los ciudadanos y en orientar un proyecto para el país, en términos metafóricos: encaminar hacia un proyecto común de futuro. De acuerdo con las correspondencias conceptuales de esta metáfora liderar corresponde a dirigir el rumbo y la educación pública corresponde a un guía. El autor recurre, nuevamente, a esta metáfora al declarar que solo cuando las decisiones no sean tomadas por la misma clase política y se consideren las voces de los actores educativos:

2. Entonces estaremos en condiciones de tener un nuevo sistema educativo de carácter público que, en un contexto democrático, nos proyecte a un futuro querido.

Esta visión sobre el estado chileno se relaciona con otras metáforas conceptuales que dan cuenta de la situación actual y de la educación pública en Chile.

Así, el autor usa la metáfora la educación pública es un botín. Se entiende por "botín" el beneficio que se obtiene de un robo, atraco o estafa, o, en el dominio bélico, las armas y provisiones de las cuales se apodera un ejército vencedor (Real Academia Española [RAE], 2014). Cualquiera sea la referencia, alude a apropiarse de algo de manera violenta o indebida. De acuerdo con esta metáfora, la educación ha sido arrebatada por el sector privado para lucrar con ella.

3. Vemos que, tal como ha sucedido con el aparato Estado, a los distintos gobiernos post dictadura les ha parecido muy institucional y natural ver al sistema educacional convertido en un apetitoso botín de sectores edu-empresariales, sectores eclesiásticos y sectores políticos (duopolio), por cierto unidos entre si para neutralizar el poder real de quienes por derecho propio (con sustento teórico y práctico) somos los llamados a pensar y trazar el rumbo en materia de política educacional y el sentido de la escuela pública, llámese profesores, estudiantes, apoderados, académicos, investigadores y el mundo social.

4. Refundar la educación pública chilena implica recuperar el poder estatal y desde alli recuperar el poder de los actores educativos y del todo social, dejando atrás la lógica de botines /.../

En el extracto 3 se identifica nuevamente la metáfora conceptual las actividades con propósito son viajes y las correspondencias ya mencionadas. Mediante esta metáfora, ahora el autor convoca al profesorado y a otros actores sociales en cuanto guías a trazar el rumbo, es decir, a asumir un liderazgo y participar en la toma de decisiones sobre las políticas educacionales, derecho que les fue arrebatado al llevarse ese botín que es la educación pública.

En síntesis, se observa una coherencia temática entre las metáforas identificadas. Al configurar al Estado con atributos humanos como la cobardía, el autor cuestiona el alcance real de la NEP y asume que no se implementará una real desmunicipalización. Castillo critica a los gobiernos desde la dictadura en adelante por haber arrebatado el carácter público a la educación, lo que le restó su rol en la sociedad, y por haber entregado su administración a los privados que la convirtieron en un botín del cual lucrar, o a los municipios, que no cuentan con los recursos suficientes para asegurar las condiciones de calidad y equidad. Al mismo tiempo, la metáfora conceptual las actividades con propósito son viajes se usa de manera positiva, pues permite concebir a la educación pública en un rol de guía que debe orientar a la sociedad en su proyecto de futuro. Junto con ello, esta metáfora se usa para convocar a los actores sociales y al profesorado a asumir un liderazgo que les fue arrebatado.

\section{“Nueva Educación Pública: ¿¿Dónde están los profesores de Chile?”}

En esta columna, César Solís, candidato a diputado por el Frente Amplio, una nueva coalición de izquierda, aborda las consecuencias de la municipalización de la educación implementada por la dictadura. Solís revisa 
los hitos en la educación pública desde el siglo XX hasta ahora para luego focalizarse en el fracaso de la educación a partir de la administración del gobierno de la dictadura. Para ello recurre a la metáfora orientacional éxito es arriba-fracaso es abajo, instanciada por una metáfora específica: el fracaso de la educación pública es abajo.

5. La década de los '80 se muestra como un periodo clave para entender la debacle en la que ha caído la educación pública. Hasta esa fecha, y con múltiples esfuerzos, el modelo educativo chileno se podia catalogar como de provisión mixta (con una clara preponderancia y rol orientador del sector público, frente a las entidades colaboradoras del estado), que lograba -con dificultadcubrir la matrícula nacional de niños y jóvenes de diversos lugares y realidades a lo largo de todo Chile.

Esta metáfora conceptual implica que en el pasado la educación estaba arriba, es decir, que era de calidad y que era significativa para el país. La metáfora conceptual permite expresar la pérdida de estas condiciones en términos de descenso. Así, en la actualidad, según el autor, el sistema de educación pública está abajo, es decir, en crisis.

El autor destaca que el profesorado tuvo un rol preponderante en la elaboración de la Constitución Política de la República de 1925, la cual "dio sustento a la política educativa que se plasmó y complementó -hasta 1980 - con reformas como las de Carlos Ibáñez del Campo, Pedro Aguirre Cerda, Eduardo Frei Montalva y la Unidad Popular". De acuerdo con Solís, esta política educativa fue descontinuada por la dictadura cívicomilitar al producirse:

6. el desmantelamiento del antiguo sistema de educación, materializándose la municipalización como la alternativa a la mejora en acceso, cobertura y ejecución de recursos públicos.

Se identifica aquí la metáfora conceptual la educación pública es un edificio. De acuerdo con el Diccionario de la RAE (2014), en su primera acepción, "desmantelar" es "echar por tierra y arruinar los muros y fortificaciones de una plaza". La siguiente acepción es "clausurar o demoler un edificio u otro tipo de construcción con el fin de interrumpir o impedir una actividad”. En el dominio fuente, el desmantelamiento involucra un agente que provoca destrucción de una estructura y de su funcionamiento. Metafóricamente, la educación pública es el edificio desmantelado y el gobierno dictatorial el agente de la destrucción mediante la implementación de la municipalización. Extendiendo la metáfora, en 1981 se desmanteló el antiguo edificio de la educación para construir uno con nuevos pilares, que fueron la base del actual sistema.

Solís afirma que durante los gobiernos postdictadura se inició un proceso de discusión para lograr la desmunicipalización. En este contexto, el columnista recuerda las protestas estudiantiles y manifestaciones sociales ocurridas durante 2006 y 2011, en las cuales la principal demanda era el derecho a una educación gratuita, pública y de calidad. El autor señala que estas manifestaciones "fueron la antesala de lo desplegado -desde el ejecutivo y ambas cámaras - a partir del gobierno de Sebastián Piñera”. Luego, se centra en el actual proyecto de Nueva Educación Pública, propuesto por el gobierno de Bachelet, el cual contempla un proyecto de ley de desmunicipalización. Se podría inferir, si seguimos las posibilidades dadas por lógica de esta metáfora conceptual, que con este proyecto se trata de reconstruir el edificio desmantelado por la dictadura, o de desmantelar el construido en ese gobierno y construir uno nuevo. Sin embargo, para Solís:

7. Luego de meses de debate y diálogo sobre esta materia, se aprecia una visible y profunda falencia. La redistribución de recursos desde el fisco sin atender a las caracteristicas particulares de los contextos locales y escolares diversos, la lógica del voucher y el pago de la deuda histórica, son pilares que no se han abordado a lo largo de este proceso.

Los pilares del edificio construido en dictadura son la falta de atención a la diversidad de contexto, la lógica del voucher y la deuda histórica a los docentes, la cual para Solís "materializa la precarización y falta de valoración con la que se tratado al profesorado nacional”. Así, en lugar de reconstruir el antiguo edificio desmantelado o de construir uno nuevo, para el columnista, se mantiene el actual sistema privatizador. En otras palabras, desde la dictadura ese nuevo edificio ha estado construyéndose con pilares sólidos que han sido mantenidos por los gobiernos democráticos. 
A continuación, se presentan las metáforas conceptuales analizadas junto con sus correspondencias conceptuales.

TABLA 2.

Metáforas conceptuales y correspondencias conceptuales

\begin{tabular}{|c|c|c|}
\hline \multirow{2}{*}{$\begin{array}{l}\text { Metáforas conceptuales } \\
\text { para educación pública }\end{array}$} & \multicolumn{2}{|l|}{ Correspondencias conceptuales } \\
\hline & Dominio meta & Dominio fuente \\
\hline \multirow{7}{*}{$\begin{array}{l}\text { La educación pública es } \\
\text { un botín }\end{array}$} & Educación pública & Bien valioso \\
\hline & Estado & Dueño del bien \\
\hline & Ceder la educación a los privados & Vender un objeto valioso \\
\hline & Entes privados & $\begin{array}{l}\text { Sujetos a los que se entregó el } \\
\text { bien }\end{array}$ \\
\hline & $\begin{array}{l}\text { Estado chileno que ha cedido } \\
\text { parte de la educación al sector } \\
\text { privado }\end{array}$ & $\begin{array}{l}\text { Persona traicionera que ha } \\
\text { vendido un objeto valioso }\end{array}$ \\
\hline & $\begin{array}{l}\text { Educación pública cedida a los } \\
\text { privados }\end{array}$ & Bien que ha sido arrebatado \\
\hline & Incrementar la educación pública & Recuperar el bien arrebatado \\
\hline \multirow{3}{*}{$\begin{array}{l}\text { La educación pública es } \\
\text { un guía }\end{array}$} & Educación pública & Guía \\
\hline & El país & Sujetos guiados \\
\hline & Objetivos a alcanzar & La meta a la cual llegar \\
\hline \multirow{4}{*}{$\begin{array}{l}\text { El fracaso de la } \\
\text { educación pública es } \\
\text { abajo }\end{array}$} & Éxito-fracaso & Arriba-abajo \\
\hline & Éxito de la educación pública & Arriba \\
\hline & Fracaso de la educación pública & Abajo \\
\hline & $\begin{array}{l}\text { Disminución de la calidad de la } \\
\text { educación pública }\end{array}$ & Descenso \\
\hline \multirow{4}{*}{$\begin{array}{l}\text { La educación pública es } \\
\text { un edificio }\end{array}$} & Educación pública & Edificio \\
\hline & $\begin{array}{l}\text { Componentes del sistema } \\
\text { educacional }\end{array}$ & Pilares del edificio \\
\hline & Gobierno de la dictadura & $\begin{array}{l}\text { Agente de destrucción del } \\
\text { edificio }\end{array}$ \\
\hline & $\begin{array}{l}\text { Transformaciones al sistema de } \\
\text { educación pública }\end{array}$ & Derribar pilares \\
\hline
\end{tabular}




\section{Conclusiones}

La columna de opinión es un tipo de texto prolífico en construcción de metáforas, puesto que constituye un espacio de debate que evidencia distintos puntos de vista, que las metáforas permiten conceptualizar y caracterizar de forma precisa. En particular, en este estudio se ha mostrado que las metáforas conceptuales que emergen desde las columnas evidencian el carácter complejo del concepto de educación pública mediante su asociación con diferentes dominios fuente, con lo cual se destacan determinadas características y valoraciones sobre este dominio.

Por una parte, la educación pública posee los rasgos de un botín y, por otra, tiene las características propias de un edificio. La configuración de la educación pública como un botín permite hacer comprensible la idea del traspaso de la administración de la educación pública desde el Estado hacia el sector privado desde una perspectiva que cuestiona dicho proceso, lo que se entiende como impropio o ilegítimo. En otros términos, el Estado es dueño y garante de un bien, pero a su vez ha traicionado y realizado acciones negativas en contra: lo ha vendido, cedido y ha permitido que el bien sea arrebatado. En un segundo caso, la educación pública se conceptualiza como un edificio, el cual se erige sobre la base de una serie de pilares correspondientes a las políticas que permiten el funcionamiento del sistema; cambiar la educación pública significa, entonces, "derribar un edificio" o "desmantelarlo", y "construir otro". Esta metáfora resulta efectiva, por ejemplo, para explicar la modificación del sistema educativo anterior a los años ochenta y su reemplazo por el actual, desde una perspectiva que también se expresa como negativa, que destaca la violencia o la "fuerza destructora" de dicho cambio. Con esta metáfora se expresa asimismo que han existido agentes destructivos de la educación pública, como es el caso del gobierno de la dictadura y los entes privados; y, por último, el Estado tiene una tarea por delante, derribar los obstáculos que afectan la calidad de la educación pública.

Esta perspectiva crítica que reflejan las metáforas está fuertemente asociada al contexto temporal y social en el que la sociedad chilena se encuentra actualmente, respecto a revalorar la educación pública y realizar los cambios necesarios para que ella alcance altos niveles de calidad. Este aspecto aparece claramente reflejado en las metáforas de las columnas de opinión y constituye un indicador de que las metáforas reflejan la compresión que los sujetos hacen de la realidad en la que están insertos, desde un contexto determinado y una temporalidad específica.

El análisis permitió identificar la presencia de diferentes tipos de metáforas, algunas estructurales, que permiten organizar y hacer comprensible un concepto mediante la estructura provista por el dominio fuente (Soriano, 2012), otras convencionales y de orden ontológico, más generales y arraigadas en nuestra experiencia humana (Kövecses, 2002/2010; Soriano, 2012), por ejemplo, las actividades con propósitos son viajes. También, se evidenciaron metáforas orientacionales, las cuales se caracterizan por otorgar coherencia a un conjunto de conceptos metafóricos, según patrones de dirección (por ejemplo, éxito es arriba-fracaso es abajo).

A pesar de las diferencias entre las metáforas, se evidencia coherencia temática entre estas, pues se complementan y no se contradicen entre sí, lo que contribuye a la coherencia intratextual de las columnas (véase Kövecses, 2002/2010). En otras palabras, las metáforas se integran a la estructura del texto y de su línea argumental, lo que permite la progresión del mismo. En muchos casos, las metáforas se profundizan y hacen explícitas las correspondencias entre dominios. Esto ocurre, por ejemplo, al conceptualizar a la educación como un "edificio" y, desde esta, referir a las políticas que la sustentan como "pilares". Como se señaló, dicha correspondencia implica que un cambio del sistema educativo solo se pueda producir mediante la "destrucción del edificio", o sea del sistema educativo, y la "construcción" de otro, aunque no se refiera esto explícitamente en las columnas. 
En términos referentes al contenido de las columnas de opinión, se destaca el hecho que ambas coinciden en sus planteamientos referidos a la educación y a la situación docente, no solo respecto al diagnóstico sino también en cuanto a propuestas. En ambos casos se plantea que la educación pública fue perjudicada por el avance de las lógicas neoliberales implementadas desde la dictadura y consolidadas bajo los gobiernos posteriores. Asimismo, las dos columnas convocan a los docentes a participar de los cambios que se están produciendo a nivel nacional en torno a la educación, como actores incidentes de dicho proceso. Esto resulta aún más destacable en la medida en que los medios en los cuales se publicaron las columnas de opinión son disímiles entre sí; La Tercera, por un lado, es uno de los periódicos de circulación nacional de mayor relevancia dentro del país; de capital privado, asume como directriz los intereses y tendencias de la sociedad. El otro medio corresponde a la página web del Colegio de profesores de Chile, gremio que se asume al servicio del conjunto del profesorado, y que actualmente está dirigido por Mario Aguilar, activo militante de izquierda.

Como proyecciones del presente trabajo, se cuentan la incorporación de determinadas perspectivas argumentativas para su articulación con el marco teórico de la metáfora conceptual, en especial las que ahondan en la dimensión pragmática de la argumentación y que consideran la situación de enunciación como parámetro desde el cual se realiza la práctica argumentativa (véase Charaudeau, 2009; Plantin, 1998). En este sentido, sería productivo estudiar las estrategias discursivas y argumentativas empleadas en las columnas de opinión y describir cómo estas se vinculan al funcionamiento de la metáfora conceptual. Por ejemplo, la metáfora, la educación pública es un botín, conceptualiza la educación como un beneficio obtenido de forma indebida por parte de un grupo que se apodera de ella para lucrarse. De esta forma, como recurso discursivo, la metáfora robustece los argumentos y contrargumentos que la columna de opinión despliega.

Desde el punto de vista de los estudios cualitativos, la metáfora conceptual se convierte en una herramienta investigativa robusta de licitación de las representaciones que los sujetos realizan de un fenómeno específico, puesto que la correspondencia entre los dominios fuente y meta produce una proyección de propiedades inferenciales en un contexto específico, lo que facilita comprender el significado de las construcciones metafóricas al momento de realizar el análisis.

\section{Agradecimientos}

Este estudio fue financiado por el Fondo Nacional de Desarrollo Científico y Tecnológico (Chile) a través del proyecto FONDECYT Regular N 1171416 "Las representaciones sociales del profesorado chileno en ciberperiódicos. Un análisis del discurso en Lingüística Cognitiva”.

\section{Referencias}

Alarcón-Hernández, P., Díaz-Larenas, C., Venegas-Carrasco, C., y Vásquez-Bustos, V. (2018). Conceptualizaciones sobre el proceso de planificación de la enseñanza. Las metáforas de futuros profesores. Íkala, Revista de Lenguaje y Cultura, 23(1), 65-81.

Alarcón-Hernández, P., Díaz-Larenas, C., y Vergara-Morales, J. (2015). Chilean preservice teachers' metaphors about the role of teachers as professionals. En W. Wan y G. Low (eds.), Elicited Metaphor Analysis in Educational Discourse (pp. 289-314). Ámsterdam, Holanda y Filadelfia, Estados Unidos: John Benjamins Publishing Company.

Alarcón-Hernández, P., Vergara-Morales, J., Concha-Moreno, R., y Díaz-Larenas, C. (2014). ¿Robots, niñeras o héroes? Conceptualizaciones metafóricas del rol del docente. Paideia, 54, 75-98.

Arancibia, M. C., y Montecino, L. (2013). El blog de comentarios a textos de opinión en ciberperiódicos: un género en constante reconstrucción. Literatura y Lingüistica, 28, 123-148.

Barlow, M., y Kemmer, S. (2000). Usage-Based Models of Language. Stanford, CA: CSLI Publications. 
Boric, G., y López, D. (2015, 4 de junio). “Profesores: más dignidad es más calidad”. The Clinic. Recuperado de http:/ /www.theclinic.cl/2015/06/04/profesores-mas-dignidad-es-mas-calidad/.

Casasanto, D. (2014). Experiential origins of mental metaphors: language, culture and the body. En M. Landau, M. D. Robinson, y B. P. Meier (eds.), The power of metaphor: Examining its influence on social life (pp. 249-268). Washington, Estados Unidos: A. P. A.

Charaudeau, P. (2009). La argumentación persuasiva. El ejemplo del discurso politico. Recuperado de http://www.patr ick-charaudeau.com/La-argumentacion-persuasivaEl.html

Chilton, P. (2004). Analysing Political Discourse: Theory and Practice. Londres: Routledge.

Colegio de Profesores de Chile. (s. f.). ¿Qué es la deuda histórica? Recuperado de http://www.colegiodeprofesores.cl /que-es-la-deuda-historica/

Croft, W. (2009). Toward a social cognitive linguistics. En V. Evans y S. Pourcel (eds.), New Directions in Cognitive Linguistics (pp. 395-420). Ámsterdam, Holanda: John Benjamins.

Croft, W., y Cruse, D. A. (2004/2008). Lingüistica Cognitiva. Madrid: Akal.

Cuenca, M. J., y Hilferty, J. (1999). Introducción a la Lingüistica Cognitiva. Barcelona: Ariel.

Dąbrowska, E., y Divjak, D. (eds.). (2015). Handbook of Cognitive Linguistics. Berlín: De Gruyter Mouton.

Evans, V., y Green, M. (2006). Cognitive Linguistics. An Introduction. Edimburgo: Edinburgh University Press Ltd.

Geeraerts, D., y Cuyckens, H. (eds.). (2007). The Oxford Handbook of Cognitive Linguistics. Oxford: University Press.

Gibbs, R. W. (2014). Conceptual metaphor in thought and social action. En M. Landau, M. D. Robinson, y B. P. Meier (eds.), The power of metaphor: Examining its influence on social life (pp. 17-40). Washington, Estados Unidos: A. P. A.

Hart, C. (2014). Construal operations in online press reports of political protests. En C. Hart y P. Cap (eds.), Contemporary Critical Discourse Studies (pp. 167-188). Londres, Reino Unido: Bloomsbury.

Hernández, R., Fernández, C., y Baptista, P. (2010). Metodología de la investigación. México D.F.: McGraw Hill.

Ibarretxe-Antuñano, I. (2013). La Lingüística Cognitiva y su lugar en la historia de la lingüística. Revista Española de Lingüistica Aplicada (RESLA), 26, 245-266.

Ibarretxe-Antuñano, I., y Valenzuela, J. (eds.). (2012). Lingüistica Cognitiva. Barcelona: Anthropos.

Johnson, M. (1987/1991). El cuerpo en la mente. Madrid: Debate.

Koller, V. (2012). How to Analyse Collective Identity in Discourse - Textual and Contextual Parameters. Critical Approaches to Discourse Analysis across Disciplines, 5(2), 19-38.

Kövecses, Z. (2002/2010). Metaphor: A practical introduction (2.a. ed.). Oxford/Nueva York: Oxford University Press.

Kövecses, Z. (2015). Where metaphors come from. Oxford: Oxford University Press.

Lakoff, G., y Johnson, M. (1980/2012). Metáforas de la vida cotidiana. Madrid: Cátedra.

Lakoff, G., y Johnson, M. (1999). Philosophy in the Flesh. The Embodied Mind and Its Challenge to Western Thought. Nueva York: Basic Books.

Landau, M., Robinson, M. D., y Meier, B. P. (eds.). (2014). The power of metaphor: Examining its influence on social life. Washington: A. P. A.

Langacker, R. (1987). Foundations of Cognitive Grammar, vol. I: Theoretical Prerequisites. Stanford: Stanford University Press.

Langacker, R. (2008). Cognitive Grammar: A Basic Introduction. Oxford: Oxford University Press.

Langacker, R. (2015). Construal. En E. Dąbrowska y D. Divjak (eds.), Handbook of cognitive linguistics (pp. 120-142). Berlín, Alemania: De Gruyter Mouton.

Mejía, J. (2000). El muestreo en investigación cualitativa. Investigaciones sociales, 4(5), 165-180.

Mizala, A., y Romaguera, R. (1998). Desempeño Escolary Elección de Escuelas: La Experiencia Chilena. Serie Economía $\mathrm{N}^{\circ}$ 36. Santiago de Chile: Universidad de Chile. Recuperado de http://www.opech.cl/bibliografico/Doc_Fina nciamiento/Desempeno_Escolar_Y_Eleccion_De_Colegios_Mizala_Romaguera.pdf 
Montecino, L., y Arancibia, M. C. (2015). Recursos de valoración en comentarios de blogs de ciberperiódicos chilenos: construcción del miedo al cambio social. Revista Latinoamericanade Estudios del Discurso, 15(2), 159-177.

Morales-López, E. (2011). Hacia dónde va el análisis del discurso. Revista Electrónica de Estudios Filológicos, (21). Recuperado de http://www.um.es/tonosdigital/znum21/secciones/estudios-21-discurso.htm

Moser, K. (2000). Metaphor analysis in psychology: method, theory, and fields of application. Forum: Qualitative Social Research, 1(2). Recuperado de http://www.qualitative-research.net/index.php/fqs/article/view/1090/2 387.

Musolff, A., y Zinken, J. (eds.). (2009). Metaphor and Discourse. Nueva York: Palgrave Macmillan.

Plantin, C. (1998). La Argumentación. Barcelona: Ariel.

Pragglejaz Group. (2007). MIP: A method for identifying metaphorically used words in discourse. Metaphor and Symbol, 22(1), 1-39.

Real Academia Española (RAE). (2014). Diccionario de la lengua española (23.a ed.). Consultado en http://dle.rae.es/

Romano, M., y Porto, M. L. (eds.). (2016). Exploring discourse strategies in social and cognitive interaction. Amsterdam: John Benjamin Publishing Company.

Ruiz, J. (2009). Análisis sociológico del discurso: métodos y lógicas familiarizados con la práctica de investigación social. Forum: Qualitative social research, 10(2). Recuperado de http://www.qualitative-research.net/index.php /fqs/article/view/1298/2776

Saban, A. (2006). Functions of Metaphor in Teaching and Teacher Education: A review essay. Teaching Education, 17(4), 299-315.

Saban, A. (2010). Prospective Teachers' Metaphorical Conceptualizations of Learner. Teaching and Teacher Education, $26,290-305$.

Saban, A., Kocbeker, B. N., y Saban, A. (2007). Prospective teachers' conceptions of teaching and learning revealed through metaphor analysis. Learning and Instruction, 17, 123-139. https://doi.org/10.1016/j.learninstruc.200 7.01 .003

Semino, E. (2008). Metaphor in discourse. Cambridge: University Press.

Soares da Silva, A. (2016). The persuasive (and manipulative) power of metaphor in 'austerity' discourse. En M. Romano y M. L. Porto (eds.), Exploring discourse strategies in social and cognitive interaction (pp. 79-108). Amsterdam, Holanda: John Benjamin Publishing Company.

Soriano, C. (2012). La metáfora conceptual. En I. Ibarretxe-Antuñano y J. Valenzuela (eds.), Lingüistica cognitiva (pp. 97-121). Barcelona: Anthropos.

Taylor, J. (2002). Cognitive Grammar. Nueva York: Oxford University Press Inc.

Thomas, L., y Beauchamp, C. (2011). Understanding New Teachers' Professional Identities through Metaphor. Teaching and Teacher Education, 27(4), 762-769.

Tomasello, M. (1999). The cultural origins of human cognition. Cambridge: Harvard University Press.

Van Dijk, T. A. (2003). Ideología y discurso. Barcelona: Ariel.

Van Dijk, T. A. (2009). Society and discourse. How social contexts influence text and talk. Cambridge: Cambridge University Press.

\section{Licencia Creative Commons CC BY 4.0}

Cómo citar este artículo: Alarcón Hernández, P., Díaz Larenas, C., y Vásquez Bustos, V. (2018). Un análisis de columnas de opinión desde la metáfora conceptual. Signo y Pensamiento, 37(73). https://doi.org/10.11 144/Javeriana.syp37-73.acom 